\title{
Avaliação da qualidade da água subterrânea na zona rural do município de Pelotas, RS
}

\section{Evaluation of groundwater quality in the rural area of the city of Pelotas, RS}

Samanta Tolentino Cecconello ${ }^{1}$, Luana Nunes Centeno², Diuliana Leandro ${ }^{3}$

\section{RESUMO}

$\mathrm{Na}$ zona rural as águas subterrâneas ainda são as fontes mais utilizadas para abastecimento humano. Sendo que a qualidade destas águas está relacionada com as diversas atividades existentes no entorno das fontes de captação de água. Este estudo teve como objetivo mapear a vulnerabilidade natural à contaminação das águas subterrâneas pelo método GOD, caracterizar a qualidade da água oriunda de fontes individuais de água para consumo humano na zona rural do município de Pelotas/RS, identificando as possíveis fontes de poluição. Foram analisados cinco poços rasos durante os meses de fevereiro a junho de 2018. As variáveis de qualidade da água analisadas foram turbidez, nitrogênio amoniacal, cloretos, potencial hidrogeniônico, coliformes totais, coliformes fecais, temperatura da água, sólidos dissolvidos totais e condutividade elétrica. Os resultados foram comparados com os padrões de potabilidade estabelecidos pela Portaria do Ministério da Saúde no 05/2017. Concluiu-se que os pontos analisados se encontram em áreas de média vulnerabilidade natural e que nos cinco pontos, houve variação ao longo do tempo na qualidade da água subterrânea, sendo consideradas impróprias para consumo humano.

Palavras-chave: Vulnerabilidade; GOD; poços rasos; análise de agrupamentos.

\section{ABSTRACT}

In rural areas like groundwater are still the most used sources for human supply. Since the quality of these waters is qualified with several existing activities, it is not from the sources of water abstraction. This study aimed to map a natural vulnerability to groundwater contamination by the GOD method, characterizing the water quality from individual sources of water for human consumption in the rural area of Pelotas / RS, identifying as possible sources of use. Five shallow points were analyzed during the months of February to June 2018. The water quality variables analyzed were turbidity, ammonia nitrogen, chlorides, hydrogen potential, total coliforms, fecal coliforms, water temperature, total dissolved and Electric conductivity. The results were compared with the potentiation standards determined by the Ministry of Health Ordinance No. 05/2017. It was concluded that the analyzed points are in

\footnotetext{
${ }^{1}$ Instituto Federal de Educação, Ciência e Tecnologia Sul-rio-grandense - IFSul, Câmpus Pelotas/RS Brasil. E-mail: satolentino@pelotas.ifsul.edu.br

${ }^{2}$ Doutoranda em Recursos Hídricos, Universidade Federal de Pelotas - UFPel, Pelotas/RS - Brasil. E-mail: luananunescenteno@gmail.com

${ }^{3}$ Universidade Federal de Pelotas - UFPel, Pelotas/RS - Brasil. E-mail: diuliana_@@hotmail.com
} 
areas of medium natural vulnerability and that in five points, there was variation over time in groundwater quality, being used for human consumption.

Keywords: Vulnerability; GOD; shallow wells; analysis of clusters.

\section{INTRODUÇÃO}

A qualidade da água subterrânea depende de muitos fatores, tais como características do solo, tipo de circulação das águas subterrâneas, através dos diferentes tipos de rochas e topografia da região e das atividades antrópicas existentes no território. (ABREU; CUNHA, 2015). Segundo Heller e Pádua (2010), verificam-se diversos usos das águas subterrâneas, dentre os quais se encontram: abastecimento individual e público, irrigação e dessedentação de animais.

O abastecimento de água em zonas rurais geralmente é feito pela captação em poços rasos (estes são poços que apresentam profundidade inferior a 20 metros e estão sob o lençol freático), pois, nestas localidades, ainda são escassas as redes públicas de distribuição de água. (Fundação Nacional da Saúde - FUNASA, 2007). Segundo o Instituto Brasileiro de Geografia e Estatística no Brasil (IBGE), em 2010, apenas 32,8\% dos domicílios brasileiros na zona rural contavam com rede de abastecimento de água de responsabilidade do poder público. A solução mais utilizada para o abastecimento de água na zona rural, ainda continua sendo as fontes individuais, ou seja, os poços rasos e profundos, poços comunitários, captação de água da chuva e distribuição por veículo transportador. (FUNASA, 2013). No Brasil, 55,3\% dos domicílios rurais são abastecidos por poços ou nascentes, e 11,9\% são abastecidos por outras fontes, como exemplo, os veículos transportadores de água. (IBGE, 2010).

Como única fonte de abastecimento de água, os poços suprem a necessidade hídrica da população local que utiliza a água para alimentação, asseio pessoal, limpeza de ambientes e outras atividades, tanto comerciais, quanto rurais. A prática artesanal e rudimentar de construção desses poços, bem como as atividades desenvolvidas no entorno deles, evidenciam a necessidade de realizar um monitoramento da qualidade da água captada, tendo em vista a preservação da saúde da comunidade local. (HELLER; PÁDUA, 2010; NOSHADI; GHAFOURIAN, 2016).

Deste modo, as contaminações das águas subterrâneas na zona rural originam-se, principalmente, pela captação de água em poços velhos e mal vedados e pela proximidade desses poços a fossas sépticas, e locais destinados à pastagem de animais. (HELLER; PÁDUA, 2010). Segundo os Cadernos de Recursos Hídricos da Agência Nacional das Águas - ANA (ANA, 2007), deve ser dada atenção especial para a vedação dos poços rasos, de forma que o aquífero e a água proveniente destes poços estejam protegidos contra possíveis contaminações. Além disso, no documento citado, é mencionada a relevância do revestimento interno dos poços rasos, o qual evita o desmoronamento das paredes, proporciona maior proteção contra infiltrações e facilita a limpeza.

A poluição biológica da água, oriunda da presença de microrganismos patogênicos geralmente provenientes de material fecal - ao atingir a rede de abastecimento ou outras fontes de água potável consumida pela população, pode ocasionar surtos 
epidêmicos de doenças intestinais, afetando um grande número de pessoas em um curto espaço de tempo. (BRAGA et al., 2015).

No Brasil, as legislações vigentes as quais tratam de potabilidade da água para consumo humano e, de águas subterrâneas são, respectivamente, a Portaria de Consolidação no 5 de 2017 do Ministério da Saúde (BRASIL, 2017) e a Resolução no 396, de 3 de abril de 2008, do Conselho Nacional do Meio Ambiente - CONAMA. (BRASIL, 2008).

A Portaria de Consolidação no 5/2017, em seu Anexo XX, dispõe sobre os procedimentos de controle e de vigilância da qualidade da água para consumo humano e seu padrão de potabilidade, porém refere-se somente aos sistemas de abastecimento e soluções alternativas coletivas de abastecimento de água, e não aos sistemas e soluções alternativas individuais de abastecimento de água, conforme tratava a antiga Portaria no 518/2004. A Resolução CONAMA no 396, de 3 de abril de 2008, dispõe sobre a classificação e diretrizes ambientais necessárias para o enquadramento das águas subterrâneas, estabelecendo, também, as condições e padrões de qualidade das águas, nas quais os parâmetros devem ser observados de acordo com os usos para os quais se destina, e que, dependendo dos usos, necessitarão ou não de tratamento para torná-las adequadas para consumo humano.

Segundo Heller e Pádua (2010) e FUNASA (2007), as soluções alternativas individuais e/ou coletivas, jamais devem ser entendidas como soluções improvisadas ou destinadas apenas a população de baixa renda, tendo em consideração que não é admitido o fornecimento de água que não atenda aos padrões de potabilidade vigentes no país. Assim sendo, é essencial o monitoramento e a avaliação de qualidade das águas subterrâneas, bem como a realização da gestão ambiental das áreas rurais, visando medidas para prevenir a intensificação das poluições.

O mapeamento da vulnerabilidade natural à contaminação de aquíferos auxilia no planejamento e gestão ambiental, servindo como instrumento de tomada à decisão. (SABADINI et al., 2017). Deste modo, é possível identificar as áreas mais vulneráveis, naturalmente restringindo, e/ou impedindo a instalação de atividades potencialmente poluidoras, bem como identificar as áreas as quais apresentam maior proteção natural e que podem ser as mais indicadas para determinadas atividades. (VILLANUEVA et al., 2015). Assim, entende-se por vulnerabilidade natural à contaminação das águas subterrâneas, a maior capacidade em resistir a modificações ao ser adversamente afetado por uma carga contaminante imposta. (FOSTER et al., 2006).

Em vista disso, podem ser planejados e melhor monitorados os usos e ocupações das áreas mais vulneráveis, assim como, conhecendo a direção e sentido do fluxo subterrâneo, podem-se considerar os riscos da alteração da qualidade natural nos mananciais subterrâneos e superficiais (KATER; OLIVEIRA, 2016), os quais são utilizados para abastecimento humano nas zonas rurais do país.

Outra ferramenta que serve de auxílio no planejamento e gestão ambiental de áreas rurais é a estatística multivariada. Essa permite a compreensão das prováveis fontes de poluição das águas subterrâneas, servindo assim, como ferramenta de gestão dos recursos hídricos. (BERTOSSI et al. 2013; HASSEN et al., 2016; GUPTA; NAYEK; CHAKRABORTY, 2016). Dentre as técnicas de estatística multivariada utilizadas nos 
estudos das águas subterrâneas, podemos citar a Análise de Componentes Principais (ACP)/Análise Fatorial (AF) e a Análise de Clusters (CA).

Segundo Hair et al. (2009), a ACP/AF visa encontrar um meio de condensar as informações contidas em diversas variáveis originais, em um conjunto menor de variáveis estatísticas (fatores) com uma perda mínima de informações. Já a AC, classifica variáveis físico-químicas e biológicas de qualidade da água em dois, ou mais grupos, com base na semelhança entre as amostras, e a semelhança global do conjunto de dados; e os resultados podem ser facilmente interpretados.

Com base no exposto, o presente estudo teve como objetivo mapear a vulnerabilidade natural à contaminação utilizando o método GOD; caracterizar a qualidade da água oriunda de fontes individuais de abastecimento de água para consumo humano, através do monitoramento das características físico-químicas e bacteriológicas, e empregar a análise estatística multivariada para identificação das possíveis fontes de contaminação dos poços rasos, na zona rural do município de Pelotas, no estado do Rio Grande do Sul, Brasil.

\section{MATERIAL E MÉTODOS}

\subsection{CARACTERIZAÇÃO DA ÁREA DE ESTUDO}

O município de Pelotas/RS, conta com aproximadamente 330 mil habitantes, sendo que apenas $6,73 \%$ da população vive na zona rural (IBGE, 2010). O abastecimento de água na zona rural do município de Pelotas/RS, foco deste estudo, é feito exclusivamente pela captação de poços do tipo escavados, cuja água é proveniente do aquífero freático raso. Segundo a Companhia de Pesquisa de Recursos Minerais CPRM (2014), o município está localizado no aquífero Litoral, domínio hidrolitológico granular e fraturado, sendo que a zona rural se apresenta, em sua totalidade, no Embasamento Fraturado Indiferenciado.

A rede de distribuição pública, a qual oferece água tratada, não contempla a parte de área rural do município. Sendo assim, a água de poços rasos é utilizada para alimentação, asseio pessoal, limpeza de ambientes e outras atividades rurais. A prática artesanal e rudimentar de construção desses poços, bem como as atividades desenvolvidas no entorno deles, evidencia a necessidade de proceder a uma análise da qualidade da água captada nestes locais, tendo em vista a preservação da saúde da comunidade local. A Figura 1 demonstra a localização da área de estudo.

\subsection{ANÁLISE QUALITATIVA: PÚBLICO ALVO}

Foram realizadas visitas mensais em cinco propriedades rurais do município de Pelotas/RS, Brasil, com o objetivo de fazer a coleta de água, além do reconhecimento da área por meio de levantamentos fotográficos e obtenção das coordenadas geográficas dos pontos de coleta com Global Positioning System - GPS (Tabela 1), e suas altitudes, sendo que para realização do levantamento das coordenadas geográficas foi utilizado o GPS GARMIN HCX®. 
Figura 1 - Mapa de localização da área de estudo.

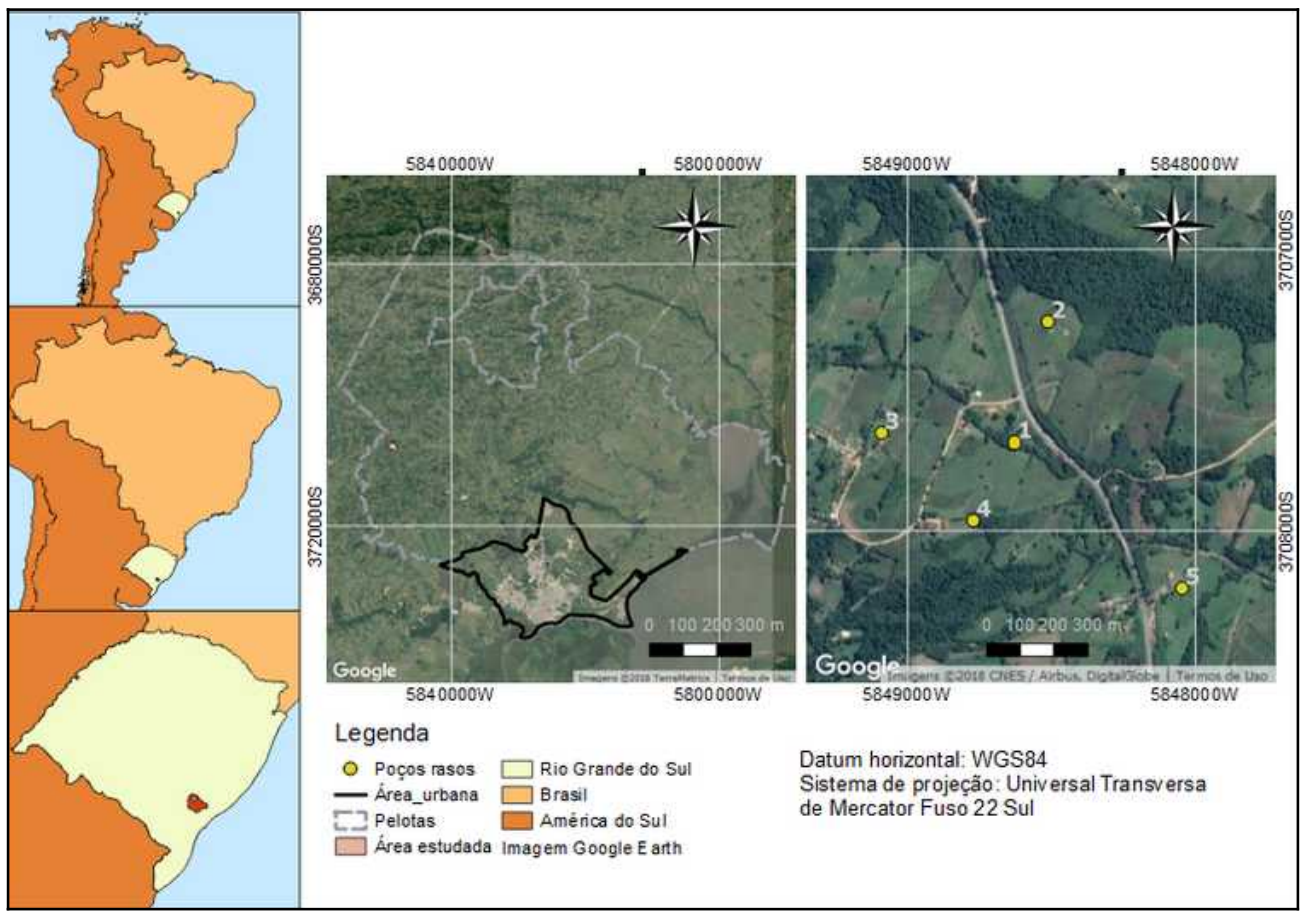

Fonte: Elaborado pelos autores.

Tabela 1 - Coordenadas geográficas dos poços estudados.

\begin{tabular}{lll}
\hline Pontos & Latitude & Longitude \\
\hline Ponto 1 & $31^{\circ} 34^{\prime} 30.94^{\prime \prime} \mathrm{S}$ & $52^{\circ} 32^{\prime} 20.92^{\prime \prime} \mathrm{O}$ \\
Ponto 2 & $31^{\circ} 34^{\prime} 19.17^{\prime \prime} \mathrm{S}$ & $52^{\circ} 32^{\prime} 17.17^{\prime \prime} \mathrm{O}$ \\
Ponto 3 & $31^{\circ} 34^{\prime} 30.07^{\prime \prime} \mathrm{S}$ & $52^{\circ} 32^{\prime} 35.70^{\prime \prime} \mathrm{O}$ \\
Ponto 4 & $31^{\circ} 34^{\prime} 38.51^{\prime \prime} \mathrm{S}$ & $52^{\circ} 32^{\prime} 25.56^{\prime \prime} \mathrm{O}$ \\
Ponto 5 & $31^{\circ} 34^{\prime} 45.16^{\prime \prime S}$ & $52^{\circ} 32^{\prime} 2.06^{\prime \prime} \mathrm{O}$ \\
\hline
\end{tabular}

Fonte: Elaborada pelos autores.

Foram identificados os locais de coleta de água como pontos 1, 2, 3, 4 e 5, por ordem de chegada. $\mathrm{O}$ critério da escolha desses pontos deu-se em decorrência da facilidade de acesso aos pontos de coleta e às residências dos usuários.

\subsection{ANÁLISE DA VULNERABILIDADE NATURAL À CONTAMINAÇÃO DO AQUÍFERO}

Para estimar o índice de vulnerabilidade natural à contaminação das águas subterrâneas do município de Pelotas/RS, utilizou-se da metodologia GOD, proposta por Foster et al., (2006). Para aplicação da metodologia GOD, é essencial a obtenção de informações referentes aos poços localizados na área de estudo, tais como: o grau de confinamento do poço; o perfil litológico e a profundidade do nível estático. Dessa forma, estes dados foram obtidos no Sistema de Informações de Águas Subterrâneas (SIAGAS), da Companhia de Pesquisa de Recursos Minerais (CPRM), Serviço Geológico do Brasil para o município de Pelotas.

Segundo informações disponibilizadas no sítio da CPRM/SIAGAS (2017), o Município de Pelotas apresenta 152 captações por poços tubulares cadastrados, porém, foram 


\section{Revista Thema}

utilizados 100 poços, sendo estes os quais continham todas as informações necessárias para aplicação do método GOD.

O primeiro parâmetro da metodologia GOD, "G" - Grau de confinamento, leva em consideração o tipo de aquífero, sendo atribuídos valores que variam entre 0 a 1,0. 0 segundo parâmetro, "O" - Ocorrência de estratos de cobertura, classifica os estratos ou camadas acima da zona saturada do aquífero, em termos do grau de consolidação e caráter litológico, e são atribuídos valores que variam em uma escala de 0,4 a 1,0. Já o último parâmetro, "D" - Distância até o lençol freático representa o nível freático, isto é, a distância entre a boca do poço e o nível da água subterrânea, variando a escala deste parâmetro entre 0,6 a 1,0. O índice de vulnerabilidade do aquífero à contaminação é determinado pelo produto dos valores obtidos para cada um dos parâmetros, variando de 0,0 (vulnerabilidade insignificante), até o valor de 1,0 (vulnerabilidade extrema), conforme pode ser observado na Figura 2.

Figura 2 - Metodologia GOD para avaliação da vulnerabilidade natural de aquíferos.

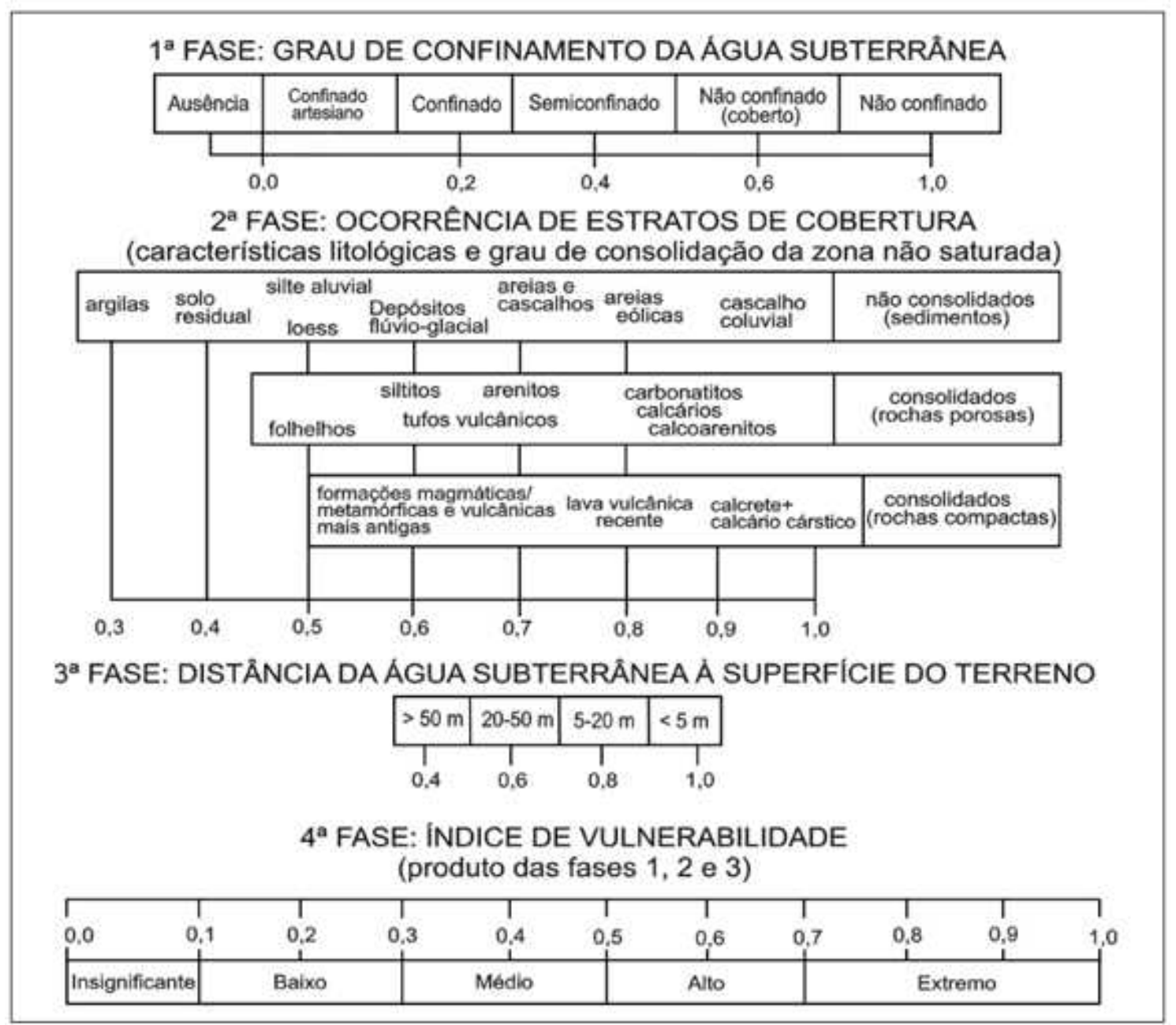

Fonte: Adaptado de Foster et al., (2006).

Utilizou-se a krigagem ordinária como interpolador para predizer o valor da variável vulnerabilidade em um ponto não amostrado, conforme Yamamoto e Landim (2013). O programa ArcGIS foi utilizado para geração do mapa de vulnerabilidade natural à 
contaminação. Neste estudo, o datum horizontal WGS-84 projeção UTM fuso 22 Sul foi adotado.

\subsection{ANÁLISE DE QUALIDADE DE ÁGUA}

Foram realizadas cinco amostragens por ponto, totalizando 25 coletas, em um período de cinco meses, que compreendeu o período de fevereiro a junho de 2018, para o monitoramento da qualidade da água. As coletas foram realizadas, transportadas e preservadas, conforme descrito no Standard Methods for Examination of Water and Wastewater, AWWA. (APHA, 2005). No momento das coletas em cada propriedade, foram realizadas perguntas aos moradores com o objetivo de conhecer as características construtivas dos poços, e a população diretamente abastecida pelo mesmo.

Após a coleta, as amostras foram transportadas até o Laboratório de Hidrodinâmica Ambiental e para o Laboratório de Análises Microbiológicas - LAMI do Instituto Federal Sul-rio-grandense - IFSul, Câmpus Pelotas, onde foram realizadas as análises físicoquímicas e microbiológicas dos pontos, conforme os procedimentos descritos no Standard Methods for Examination of Water and Wastewater, AWWA, (APHA, 2005). As análises microbiológicas foram verificadas em triplicata.

Foram analisados os teores de turbidez $(\mathrm{TH})$, nitrogênio amoniacal (NH3), cloretos $(\mathrm{Cl}-)$, potencial hidrogeniônico $(\mathrm{pH})$, coliformes totais (CT), coliformes fecais (CF), temperatura da água (TH2O), condutividade elétrica (CE) e sólidos totais dissolvidos (SDT). Os resultados obtidos foram comparados com a Portaria do Ministério da Saúde no 5/2017 e com a Resolução CONAMA no 396/2008.

\subsection{ANÁLISE DE AGRUPAMENTO}

A análise de agrupamento tem como objetivo dividir as variáveis da amostra em grupos, de forma que variáveis similares pertençam a um mesmo grupo, para isto, é essencial a definição de uma medida de similaridade entre os grupos a serem constituídos. (BERTOSSI et al., 2013; CORRAR et al., 2014). Assim sendo, se a divisão dos grupos for bem-sucedida, as variáveis no interior dos agrupamentos estarão próximas quando representadas graficamente, porém distintas dos outros grupos formados, e serão facilmente explicadas pelo pesquisador.

As variáveis de qualidade da água utilizadas neste estudo, apresentam valores reais e unidades de medidas distintas. Portanto, realizou-se o escalonamento dos dados, através da subtração da amostra pela média e, posteriormente, com o resultado, foi realizada a divisão pelo desvio-padrão, para cada variável. O escalonamento tem a função de deixar todas as variáveis na mesma unidade.

Logo após, foi adotada a distância Euclidiana, vulgarmente denominada de distância de linha reta, com o intuito de medir a similaridade entre as variáveis estudadas (MINGOTI, 2013); que representa o grau de correspondência entre objetos ao longo de todas as características usadas na análise. Para realização da análise de agrupamentos não é possível estabelecer inicialmente um número desejável de grupos a serem formados, pois dependerá da medida de distância adotada. 
O método de ligação adotado foi o método de Ward's. Segundo Hair et al. (2009) e Ferreira (2010), o método de Ward, também chamado de Mínima Variância, utiliza a medida de similaridade para aglomerar agrupamentos e, é calculado através da soma de quadrados entre dois agrupamentos acrescentados sobre todas as variáveis, este método busca combinar um pequeno número de variáveis, pois a soma de quadrados é diretamente interligada com o número de amostras envolvidas.

Bertossi et al. (2013) declaram que o corte no dendrograma pode ser estabelecido em relação às maiores distâncias em que os grupos foram formados, porém, o pesquisador deve atentar para a heterogeneidade dos dados dentro do grupo formado, para proceder a escolha do ponto de corte do dendrograma. De posse dessa informação, o ponto de corte do dendrograma vertical ocorreu em $70 \%$ pois, a partir desde ponto, encontra-se uma maior heterogeneidade dentre os grupos formados. (CORRAR et al., 2014). O dendrograma vertical formado foi lido da direita para a esquerda, nas quais o eixo das ordenadas indica a distância entre os grupos, e a posição da reta na escala. O eixo das abcissas representa os grupos unidos, por ordem decrescente de semelhança. (HAIR et al., 2009). Para a obtenção dos dendrogramas fez-se uso do software Statistica ${ }^{\circledR}$, versão 7.0.

\section{RESULTADOS E DISCUSSÃO}

\subsection{ANÁLISE QUALITATIVA DOS POÇOS RASOS}

Ao serem realizadas as coletas de água nos poços, percebeu-se que as condições construtivas e hidrossanitárias eram precárias em todos os pontos. Os poços eram do tipo cacimba, construídos de tijolos maciços, com revestimento de argamassa há mais de 10.

Das entrevistas com os moradores no momento da coleta das amostras, observou-se que a propriedade A (poço 1 ) abastece cinco adultos e duas crianças, apresenta criação de bovinos no entorno do poço, sem proteção, ou seja, os animais têm livre acesso à fonte de captação de água. O mesmo apresenta tampa quebrada, o que facilita para que os animais bebam água direto da fonte, assim como permite a entrada de folhas e outros animais.

A propriedade B (poço 2) abastece três adultos e uma criança; no entorno do poço há uma cerca que faz a proteção da fonte. A atividade agrícola da propriedade é o fumo. O poço apresenta tampa quebrada e mal vedada. Já o poço 3, abastece dois adultos, apresenta boa vedação e, na área ao entorno do poço, há cultivo de hortaliças orgânicas e milho.

A propriedade D (poço 4) abastece dois adultos e três crianças. O poço apresenta-se coberto com uma telha de cimento-amianto, portanto apresenta péssima vedação. No entorno do poço 4, há cultivo de hortaliças orgânicas e criação de equinos.

O poço 5, disponibiliza água para cinco adultos e, a atividade no entorno, era a criação de bovinos e equinos. Não havia cerca para impedir a aproximação de animais da fonte. A vedação do poço 5 era precária, pois a tampa se encontrava quebrada, permitindo a entrada de animais e folhas. 
Todos os moradores relataram nunca terem realizado a limpeza dos poços e nenhum tipo de tratamento (cloração ou fervura da água). Foram unânimes em dizer que todos os membros da família, que consomem a água, já apresentaram diarreia e parasitas intestinais. A Tabela 2 apresenta um resumo das características das propriedades estudadas.

Tabela 2 - Características dos moradores e dos poços rasos.

\begin{tabular}{|c|c|c|c|c|}
\hline \multirow[t]{2}{*}{ Propriedade } & \multicolumn{2}{|c|}{$\begin{array}{l}\text { Número de } \\
\text { moradores }\end{array}$} & \multirow{2}{*}{$\begin{array}{l}\text { Atividades existentes } \\
\text { na propriedade }\end{array}$} & \multirow{2}{*}{$\begin{array}{l}\text { Proteção da fonte de } \\
\text { abastecimento }\end{array}$} \\
\hline & Adultos & Crianças & & \\
\hline A & 5 & 2 & criação de animais & $\begin{array}{l}\text { Não existe proteção, } \\
\text { acesso livre à fonte, } \\
\text { tampa mal vedada }\end{array}$ \\
\hline B & 3 & 1 & cultivo de fumo & $\begin{array}{l}\text { Existe uma cerca que } \\
\text { limita o acesso, porém } \\
\text { tampa mal vedada }\end{array}$ \\
\hline C & 2 & - & cultivo orgânico & $\begin{array}{l}\text { Acesso restrito à fonte, } \\
\text { boa vedação da tampa }\end{array}$ \\
\hline D & 2 & 3 & $\begin{array}{l}\text { cultivo orgânico e } \\
\text { criação de animais }\end{array}$ & $\begin{array}{l}\text { Não existe proteção, } \\
\text { acesso livre à fonte, } \\
\text { tampa mal vedada }\end{array}$ \\
\hline$E$ & 5 & - & criação de animais & $\begin{array}{l}\text { Não existe proteção, } \\
\text { acesso livre à fonte, } \\
\text { tampa mal vedada }\end{array}$ \\
\hline
\end{tabular}

Fonte: Elaborada pelos autores.

\subsection{ANÁLISE DA VULNERABILIDADE NATURAL À CONTAMINAÇÃO DO AQUÍFERO}

Com relação à vulnerabilidade das águas subterrâneas, o município de Pelotas apresentou vulnerabilidade natural à contaminação, variando de baixa à alta, como demonstra a Figura 3. Porém, é importante salientar, que a vulnerabilidade natural difere de risco à poluição, pois mesmo em áreas com atividades de alto risco de poluição, podem apresentar baixa vulnerabilidade natural à contaminação, conforme estudos realizados por Borba et al. (2014) e Kater e Oliveira (2016). A vulnerabilidade de aquíferos está baseada nas características intrínsecas do ambiente.

Segundo Oliveira et al. (2016), o uso e ocupação da terra são de extrema relevância para se avaliar a qualidade das águas subterrâneas em áreas de maior vulnerabilidade à contaminação, necessitando de medidas preventivas nessas áreas.

\subsection{ANÁLISE DOS PARÂMETROS DE QUALIDADE DA ÁGUA}

As condições hidrossanitárias de todos os poços estudados favorecem que a água subterrânea, consumida pelos agricultores familiares da zona rural do município de Pelotas/RS estudados, não esteja de acordo com os parâmetros exigidos pela Portaria 5/2017 e Resolução CONAMA 396/2008. Os gráficos obtidos para cada parâmetro de qualidade da água, relacionados aos poços, podem ser observados nas Figuras de 4 a 8. A Figura 4, apresenta os teores de turbidez presentes nas águas subterrâneas da região estudada.

Foram encontrados valores de turbidez acima dos permitidos pela legislação, em todos os pontos, durante a série temporal analisada, com exceção do ponto 3 nos 
meses de fevereiro e abril. Segundo Sperling (2005), a turbidez representa o grau de interferência dos sólidos em suspensão presentes na água à passagem da luz, promovendo uma aparência turva da água. A turbidez pode ser provocada pelas atividades antropogênicas como, o lançamento de esgotos sanitários e erosão, além das provocadas pelas condições naturais, como exemplo, dissolução de rochas, proliferação de algas e microrganismos. Esses valores encontrados para a turbidez, nos cinco pontos, podem estar associados às péssimas condições hidrossanitárias em que os poços se encontravam (BRAGA, 2015), favorecendo a proliferação de insetos e decomposição de matéria orgânica.

Com relação ao parâmetro pH, tanto a Resolução 396/2008 como a Portaria 5/2017 estabelecem a mesma faixa para os parâmetros de $\mathrm{pH}$ em águas para consumo humano. Podemos observar na Figura 5, que apenas no ponto 4 a água apresentava $\mathrm{pH}$ dentro dos limites estabelecidos pela legislação, ou seja, a indicada para consumo humano deve estar entre 6,0 a 9,5. Durante o período estudado, os demais pontos apresentaram valores inferiores ao limite mínimo estabelecido para consumo humano. Mesmo apresentando um pH levemente ácido nos pontos 1, 2, 3 e 5, a água não chega a causar problemas de saúde. (PRADO et al., 2010). Essa acidez da água possivelmente esteja relacionada ao tipo de solo que, na região dos poços, é um Argissolo amarelo distrófico que apresenta baixa fertilidade natural e elevada acidez. (STRECK et al., 2008).

Os cloretos estão presentes em todas as águas de origem natural, o que varia é a quantidade destes íons e o fato de que pode ocasionar sabor salgado às águas. (SPERLING, 2005; LIBÂNIO, 2010). Os valores de cloretos encontrados neste estudo foram inferiores aos estabelecidos pela legislação, em todos os pontos, o que pode ser observado na Figura 6.

O nitrogênio e o fósforo são nutrientes necessários para o desenvolvimento das plantas, e para o desenvolvimento de diversas culturas; são utilizados sob a forma de fertilizantes químicos e/ou orgânicos. (BERTONI; NETO, 2012). Geralmente são aplicados nas lavouras e, dependendo do manejo e da conservação do solo, esses nutrientes podem ser carreados para os mananciais superficiais e, através da infiltração do solo, podem chegar às águas subterrâneas. (BRAGA, 2015). Na Figura 7 são apresentados os teores de nitrogênio amoniacal nos pontos estudados.

Podemos observar que o ponto 2 apresentou teores de nitrogênio amoniacal superiores aos limites estabelecidos pela legislação, em todos os meses, o que pode estar associado ao uso do solo no entorno do poço, como a criação de animais e agricultura intensiva. (PRADO et al., 2010). O ponto 1, apresentou teores superiores nos meses de abril, maio e junho; o que pode estar associado à mudança no uso do solo ou uma possível adubação recente.

A Figura 8 apresenta a variação dos coliformes fecais. Podemos observar que, em todos os meses estudados, os coliformes fecais apresentaram-se acima dos limites estabelecidos. Cabe ressaltar, também, que a concentração desse deve ser nula. Estas concentrações podem estar associadas às más condições hidrossanitárias em que os poços se encontravam, assim como, pelo uso e ocupação do solo no entorno dos pontos coletados. 


\section{Revista Thema}

Figura 3 - Vulnerabilidade natural à contaminação do aquífero de Pelotas/RS.

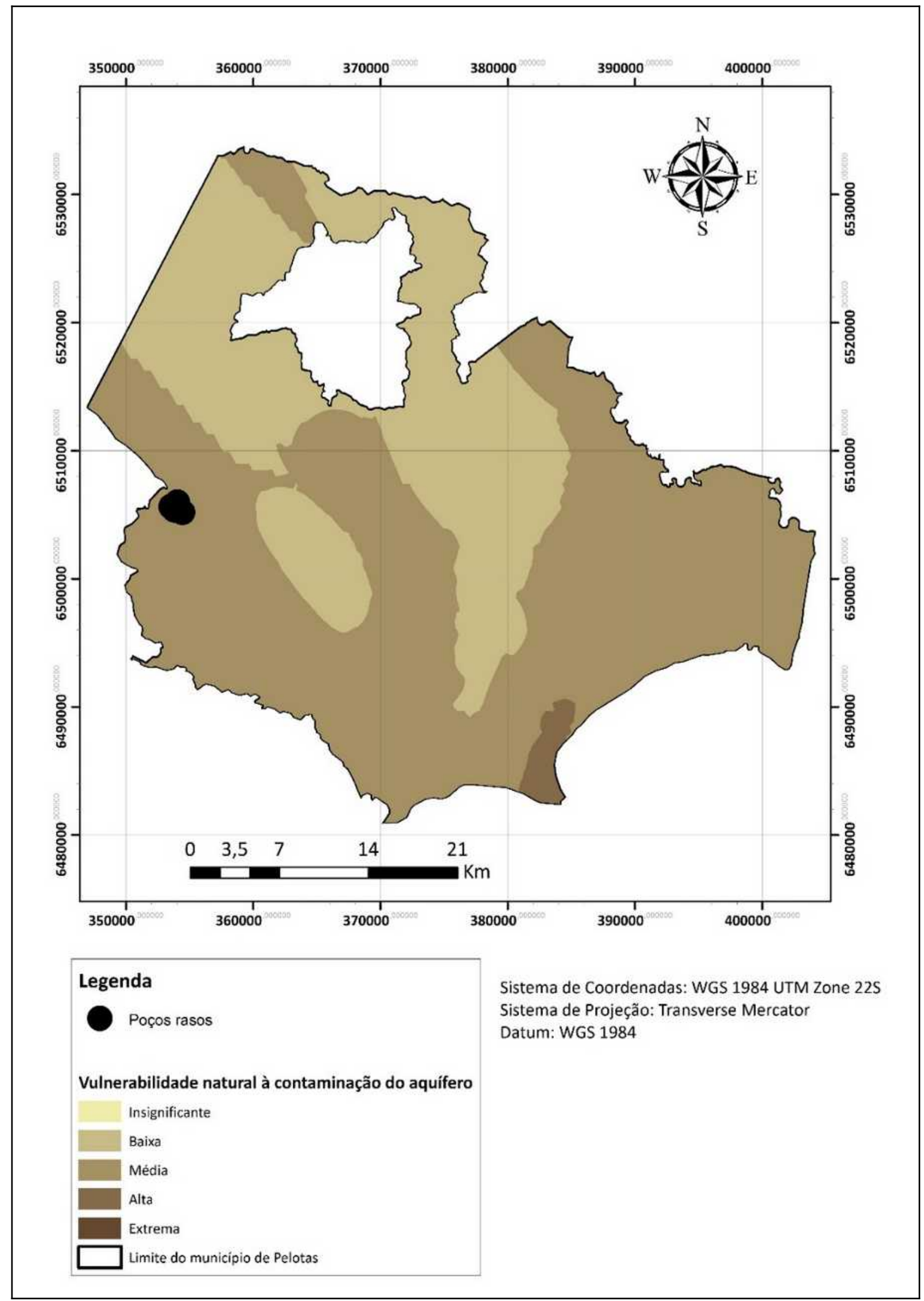

Fonte: Elaborado pelos autores. 


\section{Revista Thema}

Figura 4 - Variação da turbidez nas águas subterrâneas da zona rural do município de Pelotas.

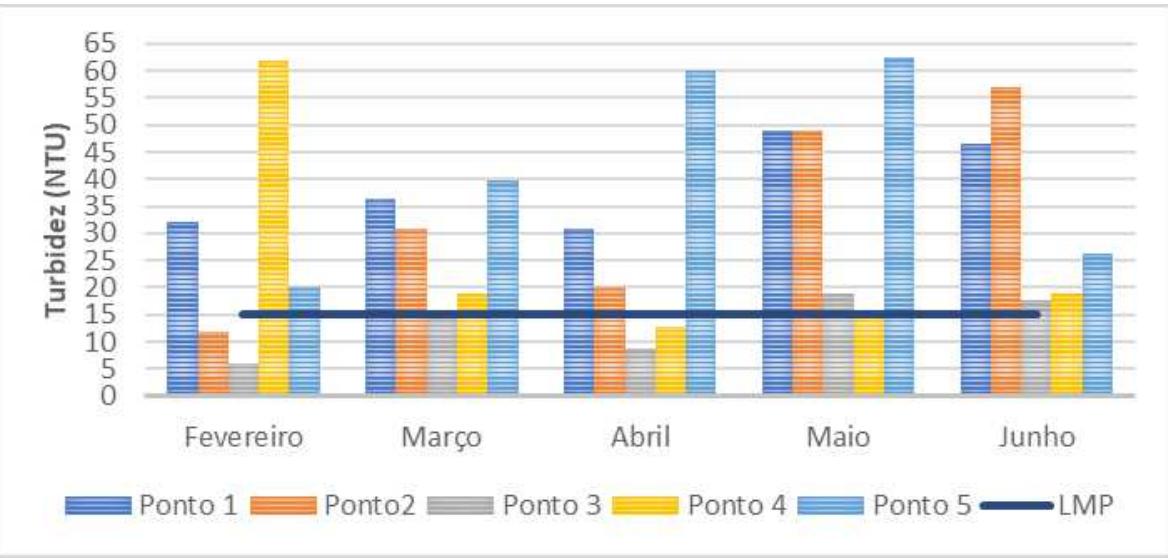

Fonte: Elaborado pelos autores.

Figura 5 - Variação do pH nas águas subterrâneas da zona rural do município de Pelotas.

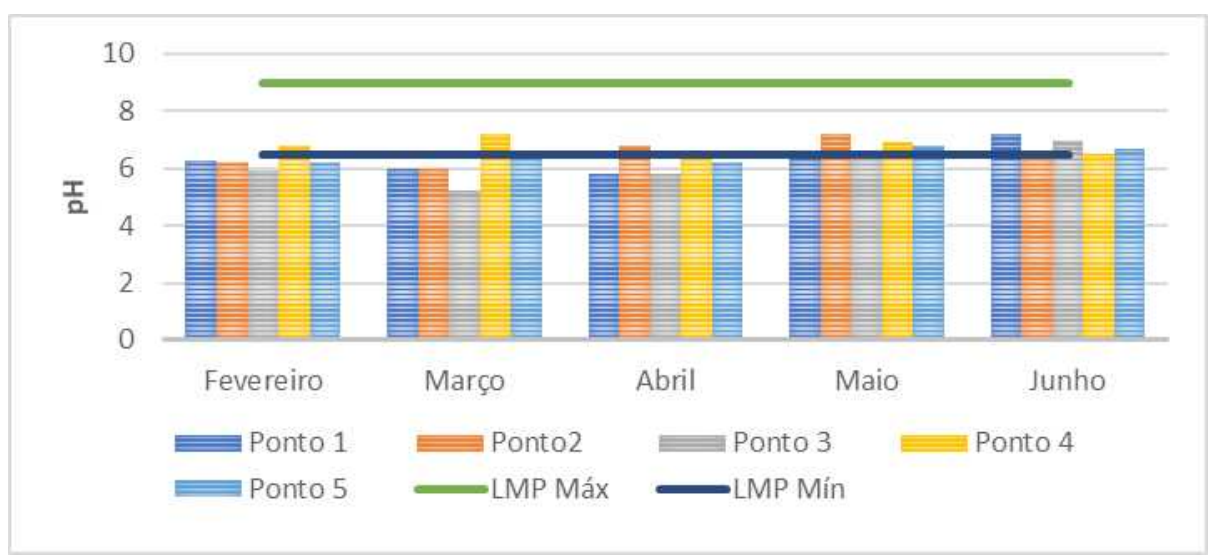

Fonte: Elaborado pelos autores.

Figura 6 - Variação dos teores de cloretos nos poços estudados.

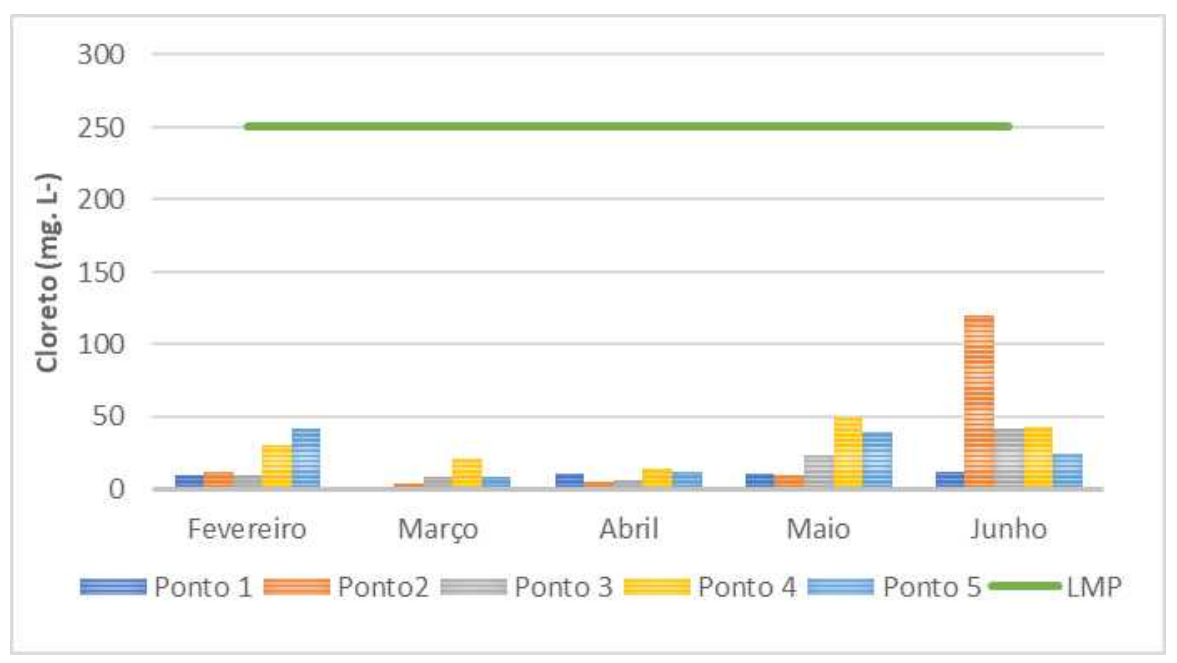

Fonte: Elaborado pelos autores. 


\section{Revista Thema}

Figura 7 - Variação dos teores de nitrogênio amoniacal nos poços da zona rural de Pelotas.

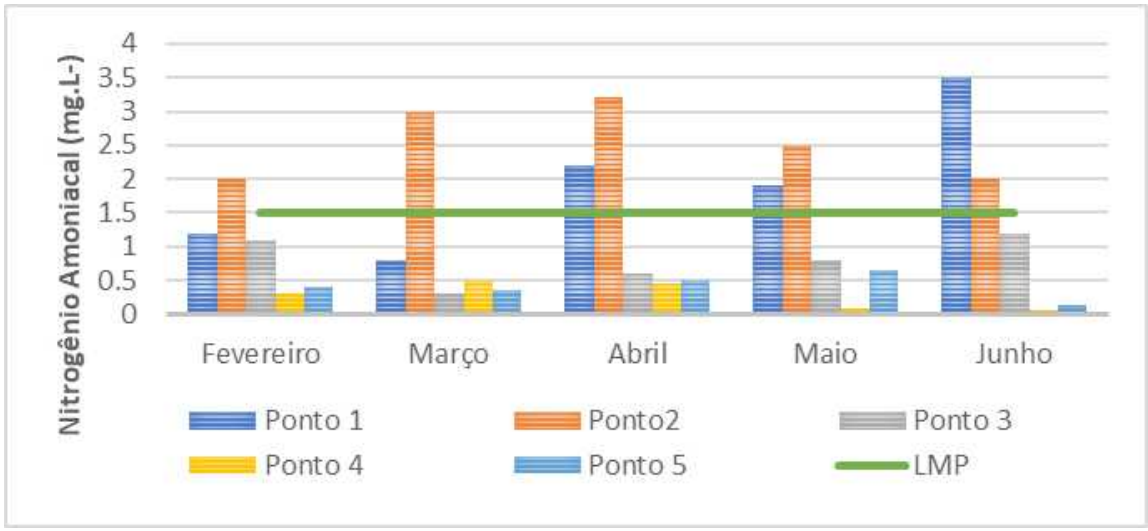

Fonte: Elaborado pelos autores.

Figura 8 - Teores de coliformes fecais encontrados nos poços da zona rural do município de Pelotas.

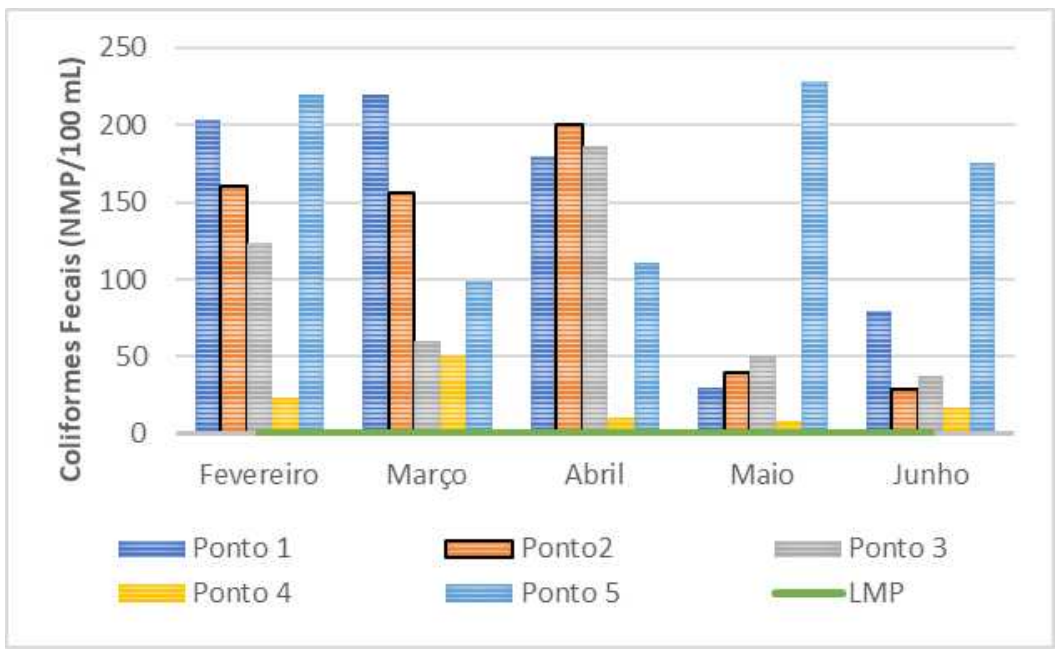

Fonte: Elaborado pelos autores.

Estes poços que apresentam teores de coliformes fecais fora do limite estabelecido pela legislação, indicam uma possível existência de microrganismos patogênicos, o que torna estas águas uma fonte potencial de transmissão de doenças de veiculação hídrica. (LIBÂNIO, 2010). Em estudos realizados por Cajazeiras (2007) e Heller e Pádua (2010), uma importante forma de contaminação das águas subterrâneas ocorre devido a uma grande variedade de organismos patogênicos que podem ser encontrados em excrementos de animais de sangue quente. Portanto, os poços monitorados durante $o$ período de estudo, são considerados, de acordo com a legislação de qualidade da água para consumo humano, impróprios.

\subsection{ANÁLISE DE AGRUPAMENTO}

A aplicação da análise de agrupamento possibilita a formação de grupos que apresentam similaridade, deste modo é possível identificar as possíveis fontes de contaminação. (CENTENO et al., 2017). O agrupamento das variáveis de qualidade da água formou um dendrograma com as 9 variáveis (Figura 9). 


\section{Revista Thema}

Na Figura 9 escolheu-se o percentual de $70 \%$ como ponto de corte satisfatório para formação dos grupos de similaridade pois, a partir desse, ocorre um maior distanciamento na medida de similaridade para a formação dos grupos. Em estudos realizados por Bertossi et al. (2013), o critério para realização do corte se deu de modo que obtivessem um maior número de grupos, os mesmos sendo estabelecidos em relação às maiores distâncias em que os grupos foram formados, levando-se sempre em consideração os critérios adotados por cada pesquisador.

O dendrograma obtido indicou a formação de dois grupos homogêneos, sendo que o primeiro grupo possui, como variáveis de qualidade de água, CT, TH2O, SDT, CF e NH3 e, o segundo grupo é formado pelas variáveis $\mathrm{Cl}-, \mathrm{pH}, \mathrm{CE}$ e TH.

Figura 9 - Dendrograma formado com as nove variáveis de qualidade da água subterrânea analisadas.

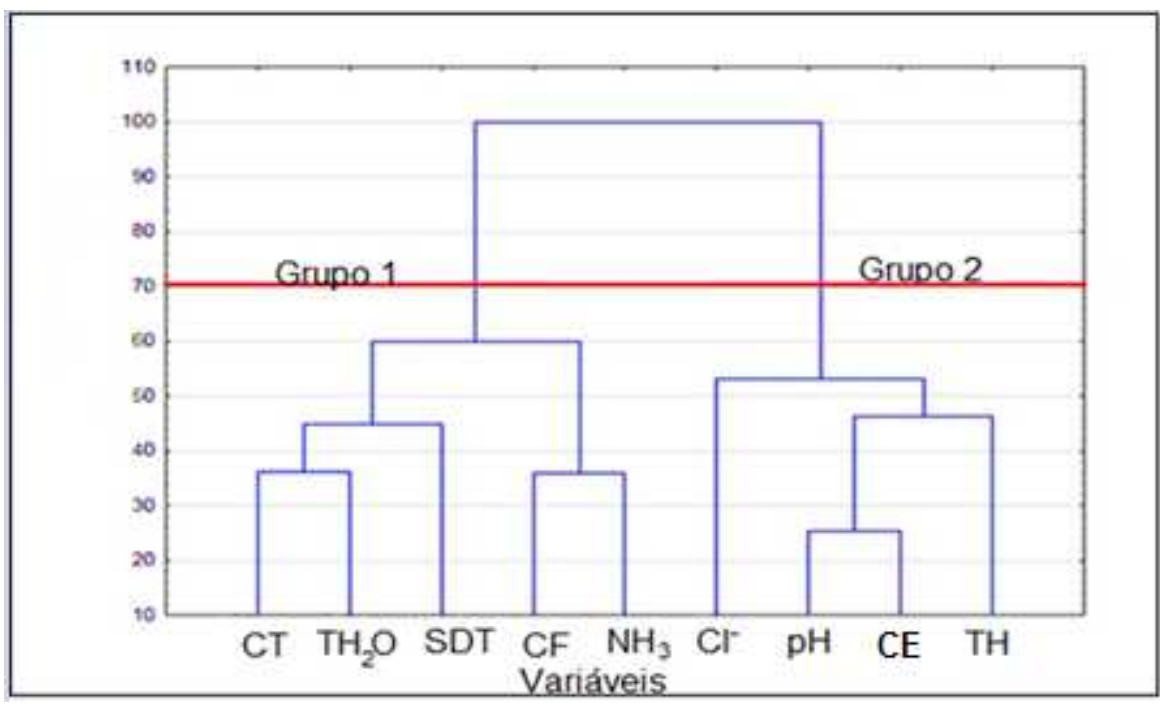

Fonte: Elaborado pelos autores.

O primeiro grupo formado possivelmente esteja relacionado à atividades antrópicas e agropecuárias; o manejo inadequado do solo, através de adubação química; pesticidas e herbicidas e também relacionado à atividades pecuárias, devido ao grupo dos coliformes estar presente neste. (SPERLING, 2005). Podendo também estar relacionado à poluições de origem natural decorrente da infiltração da água no solo e, assim favorecendo a dissolução de compostos do solo. (PRADO et al., 2010).

Já o segundo grupo, possivelmente, esteja relacionado a lixiviação de sedimentos e minerais por conta das práticas agrícolas inadequadas e despejos domésticos. (LIBÂNIO, 2010). Quando associadas às fontes naturais, essas variáveis podem ter relação com a dissolução de minerais, ou lixiviação de águas salinas decorrentes de algum tipo de adubação por resultado ao uso inadequado de procedimentos de irrigação, a presença de grande quantia de ferro e manganês nos arredores dos poços, dentre outras partículas de rocha, argila e silte. (SPERLING, 2005).

\section{CONCLUSÃO}

Com esse estudo, pode-se concluir que a qualidade das águas subterrâneas, nos pontos estudados da zona rural do município de Pelotas, apresentou-se imprópria para 
consumo humano, segundo a legislação vigente, necessitando assim, de estudos aprofundados sobre o uso e ocupação do solo na área do entorno dos poços rasos e medidas para a gestão do solo e da água subterrânea.

Com relação à determinação da vulnerabilidade natural à contaminação das águas subterrâneas no município, pode-se verificar que os poços rasos estudados se encontram em áreas de média vulnerabilidade natural, necessitando de medidas de planejamento e gestão das atividades desenvolvidas nesta região. Como forma de adequar a qualidade da água, para que essa possa ser consumida de forma segura pelos moradores, recomenda-se que sejam realizadas a manutenção e vedação dos poços, e a implementação de sistemas de cloração da água, a fim de minimizar a presença de microrganismos patogênicos causadores de doenças.

Além disso, com a aplicação da análise de agrupamento, foi possível concluir que o dendrograma obtido indicou a formação de dois grupos homogêneos, sendo que o primeiro grupo formado, possivelmente, esteja relacionado às atividades agropecuárias e ao manejo inadequado do solo; e o segundo grupo, possivelmente associado à lixiviação de sedimentos e minerais.

\section{REFERÊNCIAS BIBLIOGRÁFICAS}

ABREU, C. H. M.; CUNHA, A. C. Qualidade da água em ecossistemas aquáticos tropicais sob impactos ambientais no Baixo Rio Jari-AP: revisão descritiva. Biota Amazônia, v.5, n.2, p.119-131, 2015.

AGÊNCIA NACIONAL DE ÁGUA (ANA). Panorama do enquadramento dos corpos d'água do Brasil e Panorama da qualidade das águas subterrâneas no Brasil. Brasília: ANA, 2007.

AMERICAN PUBLIC HEALTH ASSOCIATION - APHA. Standard methods for the examination of water and wastewater. 21. ed. Washington: American Public Health Association. APHA/AWWA/WEF, 2005.

BERTONI, J.; LOMBARDI NETO, F. Conservação do solo. 8. ed. São Paulo: Ícone, 2012. BERTOSSI, A. P. A. et al. Seleção e agrupamento de indicadores da qualidade de águas utilizando estatística multivariada. Semina: Ciências Agrárias, Londrina, v.34, n.5, p.2025-2036, set. 2013.

BORBA, W. F. et al. Vulnerabilidade do aquífero à contaminação no município de Seberi/RS. Revista Monografias Ambientais - Remoa, [s.I.], v.14, n.1, p.29602966, fev. 2014.

BRAGA, B. et al. Águas Doces no Brasil: capital ecológico, uso e conservação. 4. ed. São Paulo: Escrituras, 2015.

BRASIL. Serviço de Informações de Água Subterrânea - SIAGAS. 2011.

Disponível em: <http://siagasweb.cprm.gov.br/layout/pesquisa_complexa.php>. Acesso em: 20 ago. 2017. 
BRASIL. MINISTÉRIO DA SAÚDE. Portaria de Consolidação no 5, de 03 de outubro de 2017. ANEXO XX. Dispõe sobre os procedimentos de controle e de vigilância da qualidade da água para consumo humano e seu padrão de potabilidade. Brasília: 2017.

CAJAZEIRAS, C. C. de A. Qualidade e uso das águas subterrâneas e a relação com doenças de veiculação hídrica, Região de Crajubar/CE. 2007. 131 f. Dissertação (Mestrado em Geologia) - Universidade Federal do Ceará, Fortaleza, 2007. CENTENO, L. N. et al. Monitoramento da qualidade da água do arroio São Lourenço/RS. Revista de Ciência e Inovação, Farroupilha, v.1, n.2, p.67-76, jun. 2017.

COMPANHIA DE PESQUISA DE RECURSOS MINERAIS - CPRM. Mapa hidrogeológico do Brasil ao milionésimo. Ministério de minas e Energia - Secretaria de geologia, Mineração e Transformação Mineral. Brasília: 2014. Escala 1:5.000.000.

CONSELHO NACIONAL DO MEIO AMBIENTE. Resolução $\mathbf{n}^{\circ} \mathbf{3 9 6}$, de $\mathbf{3}$ de abril de 2008. Dispõe sobre a classificação e diretrizes ambientais para o enquadramento das águas subterrâneas e dá outras providências. Diário Oficial [da] República Federativa do Brasil, Brasília, DF, 7 abr. 2008. p.66-68. Disponível em: <http://www.mma.gov.br /port/conama/legiabre.cfm?codlegi=562 >. Acesso em: 12 fev. 2017.

CORRAR, L. J; PAULO, E.; DIAS FILHO, J. M. Análise multivariada para os cursos de administração, ciências contábeis e economia. 5. ed. - Reimpressão. São Paulo: Atlas, 2014.

FERREIRA, D. F. Estatística multivariada. 2. ed. Lavras: UFLA, 2010.

FOSTER, S. et al. Proteção da qualidade da água subterrânea: um guia para empresas de abastecimento de água, órgãos municipais e agências ambientais. Edição brasileira. São Paulo: SERVMAR - Serviços Técnicos Ambientais Ltda., 2006.

FUNDAÇÃO NACIONAL DA SAÚDE (FUNASA). Manual de Saneamento: Orientações Técnicas. Brasília: Ministério da Saúde, 2007. Disponível em: < http://www.funasa. gov.br/site/wp-content/files_mf/eng_saneam2.pdf>. Acesso em: 22 abr. 2017.

FUNDAÇÃO NACIONAL DA SAÚDE (FUNASA). Manual prático de análise de água. 4. ed. Brasília: Ministério da Saúde, 2013.

GUPTA, S.; NAYEK, S.; CHAKRABORTY, D. Hydrochemical evaluation of Rangit river, Sikkim, India: using Water Quality Index and multivariate statistics. Environmental Earth Sciences, [s.I.], v.75, n.7, p.567-581, 26 mar. 2017.

HAIR JR., J. F. et al. Análise multivariada de dados. 6. ed. Porto Alegre: Bookman, 2009. 688 p.

HASSEN, I.; H. AMZAOUI-AZAZA, F.; BOUHLILA, R. Application of multivariate statistical analysis and hydrochemical and isotopic investigations for evaluation of groundwater quality and its suitability for drinking and agriculture purposes: case of Oum AliThelepte aquifer, central Tunisia. Environmental Monitoring and Assessment, [s.I.], v.188, n.3, p.135-155, 2 fev. 2017.

HELLER, L.; PÁDUA, L. Abastecimento de água para consumo humano. 2. ed. Belo Horizonte: UFMG, v.1, 2010. 
INSTITUTO BRASILEIRO DE GEOGRAFIA E ESTATÍSTICA (IBGE). Cidades@: Rio Grande do Sul/ Pelotas. Censo Demográfico 2010: Sinopse Download de Censo Demográfico 2010 - Sinopse em arquivo. CSV para Excel. IBGE, 2010. Disponível em: $<$ http://www.cidades.ibge.gov.br/xtras/perfil.php?lang=\&codmun $=431440 \&$ search $=$ rio-grande-do-sul|pelotas/infograficos:-informacoes-completas $>$. Acesso em: 2 jan. 2018.

KATER, K. V.; OLIVEIRA, F. M. Vulnerabilidade de aquíferos: caso dos cemitérios de Igarassu e Itapissuma, PE. Revista de Geologia, [s.I.], v.29, n.2, p.247-261, 2016.

LIBÂNIO, M. Fundamentos de qualidade e tratamento de água. Campinas: Átomo, 2010.

\section{MINGOTI, S. A. Análise de dados através de métodos de estatística} multivariada: uma abordagem aplicada. 2. ed. Minas Gerais: UFMG, 2013.

NOSHADI, M.; GHAFOURIAN, A. Groundwater quality analysis using multivariate statistical techniques (case study: Fars province, Iran). Environmental Monitoring and Assessment, [s.I.], v.188, n.7, p.418-431, jun. 2016.

OLIVEIRA, G. A. et al. avaliação da vulnerabilidade intrínseca das águas subterrâneas do município de Porto Velho/RO. Revista de Engenharia e Tecnologia, v.8, n.2, p.187-198, ago. 2016.

PRADO, R. B.; TURETTA, A. P. D.; ANDRADE, A. G. de (Org.). Manejo e conservação do solo e da água no contexto das mudanças ambientais. Rio de Janeiro: Embrapa Solos, 2010. 486 p.

SABADINI, S. C. et al. Potencial de vulnerabilidade natural de aquíferos à contaminação no quadrilátero ferrífero, Minas Gerais e sua relação com a atividade minerária de ouro. Caderno de Geografia, [s.I.], v.27, n.49, p.340-352, mai. 2017. Pontifícia Universidade Católica de Minas Gerais.

SPERLING, M. V. Introdução à qualidade das águas e ao tratamento de esgotos. 3. ed. Belo Horizonte: DESA - UFMG, v.1, 2005.

STRECK, E. V. et al. Solos do Rio Grande do Sul. 2. ed. Porto Alegre: EMATER/RS, 2008.

VILLANUEVA, T. Aplicação do método COP para avaliação da vulnerabilidade intrínseca à contaminação do aquífero cárstico salitre, Irecê-BA, Brasil. Brazilian Journal of Aquatic Science and Technology - BJAST, [s.I.], v.1, n.19, p.55-65, 2015.

YAMAMOTO, J. K.; LANDIM, P. M. B. Geoestatística: conceitos e aplicações. São Paulo: Oficina do Livro, 2013. 